\title{
Evolutionary origins and persistence of infidelity in Malurus: the least faithful birds
}

\author{
Andrew Cockburn ${ }^{\mathrm{A}, \mathrm{B}}$, Lyanne Brouwer ${ }^{\mathrm{A}}$, Michael C. Double ${ }^{\mathrm{A}}$, Nicolas Margraf ${ }^{\mathrm{A}}$ \\ and Martijn van de $\mathrm{Pol}^{\mathrm{A}}$ \\ AEvolution, Ecology and Genetics, Research School of Biology, The Australian National University, \\ Canberra, ACT 0200, Australia. \\ ${ }^{B}$ Corresponding author. Email: andrew.cockburn@anu.edu.au
}

\begin{abstract}
Fairy-wrens (genus Malurus) maintain territories year round, and breed cooperatively, with all members of the social group provisioning young. Despite living with several adult males, the breeding female typically cuckolds all of them, seeking fertilisations from extra-group males that provide no care to her offspring, instead caring for the young reared on their own territory. We trace the evolutionary origins and persistence of this extraordinary combination of traits. We argue that the high rate of infidelity in some fairy-wrens facilitates social pairing among nuclear family relatives, rather than being an evolutionary response to avoid inbreeding. It seems likely that females mate with extra-group males to improve the genetic quality of their offspring. The ability of males to maintain breeding plumage for long periods is the primary criterion for female choice; only older males can do so. Several features of the mating system undermine the accuracy of female choice, and low-quality males exploit this uncertainty. Extra-group matings by low-quality males can help stabilise the mating system but may leave it vulnerable to collapse under certain circumstances. Nonetheless, sexual selection in most species is very strong, confirming the utility of fairy-wrens as model organisms for the study of mate choice and intersexual selection.
\end{abstract}

Additional keywords: cooperative breeding, extra-pair copulation, fairy-wren, Maluridae, sperm competition.

Received 14 October 2012, accepted 29 November 2012, published online 15 August 2013

\section{Introduction}

In most species of birds, males and females form socially monogamous relationships, either in simple unassisted pairs, or in cooperatively breeding groups. Although there were many early hints of infidelity among birds (Birkhead and Møller 1992), it was only the invention of robust genetic methods of determining parentage that led to the discovery that many birds frequently engage in extra-pair mating and, hence, that females cuckold the male to which they are paired. However, for most avian species, the home male gains most parentage, even when the female routinely copulates with extra-pair males (Griffith et al. 2002). Among all birds, the Australian songbird genus Malurus (fairy-wrens) stands out for the sheer scale of female infidelity. In all but one species where genetic parentage has been determined, extra-pair males dominate fertilisations. Fairy-wrens are facultative cooperative breeders and there may be multiple males on the territory with the breeding female (Cockburn 2006; Rowley and Russell 1997). However, where proper exclusion tests have been applied, it is not subordinate males on the territory but males from other social groups (extra-group males) that are the dominant contributors to fertilisation (Rowley and Russell 1990; Mulder et al. 1994; Dunn and Cockburn 1999; Webster et al. 2004, 2008; Brouwer et al. 2011).
The extremely high rates of infidelity of fairy-wrens pose a huge problem that lies at the intersection of two of the main strands in behavioural ecology. First, contrary to the kin-selection hypothesis that underpins our understanding of cooperative breeding, males routinely provide substantial parental care to young to which they are completely unrelated (Dunn et al. 1995). Second, females routinely mate with males from which they obtain nothing but DNA, suggesting that, as in lekking species, females must gain genetic benefits that enhance the quality of their offspring. This in turn raises the lek paradox. Strong directional selection for male genotype should rapidly fix favourable and eliminate unfavourable alleles, eliminating genetic differences between males. There should therefore be few sustained benefits to female choice for genetic benefits.

In this contribution we review what is known about extra-pair mating and courtship in fairy-wrens. We consider why extra-pair mating is so extraordinarily prevalent, what cues females might use to choose among males, the benefits that they might obtain from infidelity, and how the conflict between males and females over infidelity can be resolved in a way that renders the mating system surprisingly resistant to evolutionary change. We deliberately speculate about areas of uncertainty in order to encourage focus on unanswered problems and hypotheses that await testing. 


\section{How widespread is infidelity in the Maluridae?}

The Maluridae are confined to the Australo-Papuan region. Current phylogenetic hypotheses support recognition of six genera (Joseph et al. 2013; Fig. 1). Two of these occur exclusively in Australia (Amytornis (grasswrens) and Stipiturus (emuwrens)) and three monospecific genera that are each other's closest relatives occur only in the Papuan region (Clytomyias, Sipodotus, Chenorhamphus). The sixth genus, Malurus (fairywrens), is distributed throughout the Australo-Papuan region, with the primary division being between the Papuan endemic Emperor Fairy-wren (M. cyanocephalus), and the remaining species, which, with the exception of the White-shouldered Fairy-wren ( $M$. alboscapulatus), is Australian. Within the Australian Malurus, there are three well defined groups: (1) the chestnut-shouldered group, comprising the Lovely (M. amabilis), Variegated (M. lamberti), Red-winged (M. elegans) and Bluebreasted (M. pulcherrimus) Fairy-wrens; (2) the bicoloured group, comprising the Red-backed ( $M$. melanocephalus), White-winged (M. leucopterus) and White-shouldered Fairywrens and (3) the blue group, comprising the Superb (M. cyaneus) and Splendid (M. splendens) Fairy-wrens. The phylogenetic position of the last species, the Purple-crowned Fairy-wren ( $M$. coronatus), relative to these three groups remains ambiguous, which as we shall see, confounds interpretation of the evolution and maintenance of infidelity.

Molecular dissection of parentage is available from all of the main clades of Australian Malurus, including the Purplecrowned Fairy-wren, and one species of Stipiturus (emu-wrens). The extent of extra-pair fertilisations is highly bimodal, with modest levels of extra-pair mating in Purple-crowned Fairywrens (4.4\%; Kingma et al. 2009) and Southern Emu-wrens

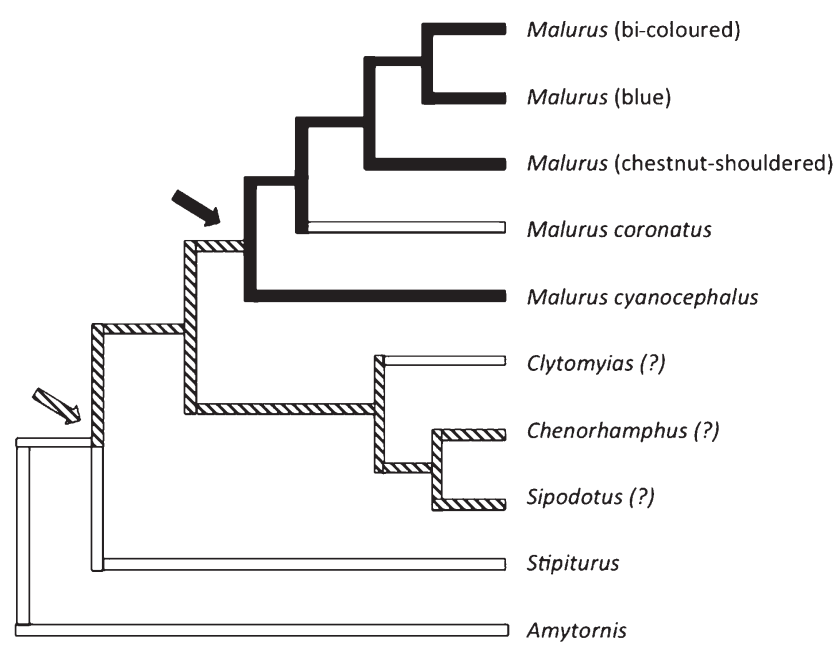

Fig. 1. Possible evolutionary scenarios for the evolution of high rates of infidelity mapped onto the phylogeny of the Maluridae (the latter adapted from Driskell et al. 2011; Lee et al. 2012; Joseph et al. 2013). Branches of the groups whose behaviour or morphology are consistent with high rates of infidelity are in black, indicating that the ancestor of Malurus was likely to have high rates of infidelity, with the trait being lost in Purple-crowned Fairywrens. An alternative scenario that cannot be tested would place the point of origin where Malurus shares ancestry with the endemic Papuan clade (black hatching), with the possibility of a secondary loss in the drably coloured Clytomyias. Arrows illustrate the likely points of origins for these scenarios.
(Stipiturus malachurus) (12\%; Maguire and Mulder 2008), and rates of extra-group parentage exceeding $50 \%$ in all the other well-studied species (Red-winged, Red-backed, Superb and Splendid Fairy-wrens; Rowley and Russell 1990; Mulder et al. 1994; Dunn and Cockburn 1999; Webster et al. 2004, 2008; Colombelli-Négrel et al. 2009; Brouwer et al. 2011). Several attempts have been made to infer the characteristics of the species that have yet to be studied. The most informative have been based on the size of the cloacal protuberance, the sperm storage organ of males (Karubian 2001; Rowe and Pruett-Jones 2008; Kingma et al. 2009). These methods successfully predict low extra-group mating rates in emu-wrens and Purple-crowned Fairy-wrens, and suggest that the grasswrens (Amytornis) are also likely to have low rates of infidelity.

Interpretation of evolutionary change depends on relationships among Malurus and the three Papuan genera that are its sister group (Fig. 1). Inference from observations of testes or cloacal protuberances is rendered uncertain in the New Guinean clade that is sister to Malurus because few specimens have been collected the length of the breeding season is not certainly known. All three of the Papuan genera tend to be sexually monochromatic compared to their Australian counterparts, but in two (Chenorhamphus, Sipodotus) both sexes are brightly coloured and have erectile cheek-patches that other species use in extra-group courtship, and in the third (Clytomyias) both sexes are comparatively drab. The monochromatism of the two brightly coloured species is difficult to interpret, as phylogenetic analyses of other tropical groups have suggested bright colouration can be the ancestral trait, and that drab colouration in females can arise secondarily in temperate species (Friedman et al. 2009). Either way, it is possible that the common ancestor of this group and Malurus had high levels of infidelity (Fig. 1).

Despite the availability of several phylogenetic analyses of Malurus, the position of the pivotal Purple-crowned Fairy-wren remains equivocal. If it is sister to the blue group, as suggested by Gardner et al. (2010), or to the chestnut-shouldered group, as argued by Driskell et al. (2011), it seems certain that its comparative fidelity is derived from promiscuous ancestors. However, the most comprehensive analysis suggests it may be an outgroup to the other Australian species (Lee et al. 2012; Joseph et al. 2013), which focuses attention on the behaviour of the New Guinean outgroup represented by the Emperor Fairywren (Fig. 1) Unfortunately, this species has not been subject to detailed behavioural study, and the few observations that are available were largely made before the level of infidelity in other fairy-wrens was well understood. There are likely to be great difficulties in remedying this deficiency, as the birds commonly skulk in dense thickets of vines and will be difficult to study. However, Schodde and Weatherly (1982) describe a male display in this species that involves flaring the pale blue cheek-feathers, and Coates (1990) includes a photograph of a male that may be displaying. Although such behaviour was interpreted in these older works as serving a function in territorial defence, in other Malurus such displays were subsequently shown to be indicative of extra-group courtship (see below), and Schodde and Weatherly (1982) incorrectly described extra-group courtship displays in Superb Fairy-wrens as a territorial display. If the reported displays by Emperor fairy-wrens also indicate extra-group courtship rather than terri- 
torial defence, it would confirm that the fidelity of Purplecrowned Fairy-wrens is secondarily derived.

In summary, available evidence suggests that high rates of promiscuity have evolved just once (in the common ancestor of Malurus) but has been lost in the Purple-crowned Fairy-wren. An alternative, but currently unsupported, scenario is that it has evolved once in the ancestor of Malurus and the Papuan clade, and has been lost twice (in the Purple-crowned Fairywren and Clytomyias; see Fig. 1). Regardless, the persistence of high levels of infidelity through multiple speciation events in an old clade of birds suggests that the mating system can be evolutionary stable over long periods, which is surprising given the conflict between males and females that must arise when rates of infidelity are high.

\section{Are there any other species like fairy-wrens?}

An alternative approach to inferring the course of evolution is to find other cases where comparable evolutionary changes have taken place. The obvious starting point is other birds where extra-pair fertilisation rates exceed $50 \%$, although such high rates of infidelity are extremely rare (Griffith et al. 2002; Westneat and Stewart 2003). There has been extensive study of two such species, and neither exhibits strong parallels to fairy-wrens. Both species are at least partially migratory and lack year-round territories, and neither species is a cooperative breeder.

In Tree Swallows (Tachycineta bicolor), there is some evidence that particular males monopolise extra-pair fertilisations (Bitton et al. 2007) but also that females mate with several males each fertile period (Kempenaers et al. 1999; Dunn et al. 2009), perhaps to increase heterozygosity in their young (Stapleton et al. 2007). Females do not consistently choose the same males from one brood to the next (Whittingham et al. 2006). In Reed Buntings (Emberiza schoeniclus), there is evidence that males punish females that cuckold them (Dixon et al. 1994; Suter et al. 2009). There is contradictory evidence as to whether females pick males with high quality or compatible genotypes (Kleven and Lifjeld 2004; Bouwman et al. 2006; Suter et al. 2007). Some studies suggest that old males dominate fertilisations (Bouwman and Komdeur 2005; Kleven and Lifjeld 2005; Bouwman et al. 2007), although this could be because of intrasexual competition among males. Test of key hypotheses remain weak in these and many other species that show lower levels of extra-pair mating (Griffith et al. 2002; Schmoll 2011). Most critical for the purposes of this review is that we will demonstrate below that few of the key features of other promiscuous species apply in Malurus, undermining comparative analysis of the conditions leading to selection and maintenance of high rates of infidelity.

The most curious case of high rates of infidelity, which remains poorly understood, occurs in the Australian Magpie (Gymnorhina tibicen), where the rate of extra-pair mating in at least one population exceeds that in Malurus (Hughes et al. 2003). This species exhibits extraordinary between-population diversity in social systems. In some populations, the birds are plural breeders, with several pairs breeding on a single territory and attracting care from supernumerary helpers (Hughes et al. 2003). In other populations, a single pair breeds on the territory, and is helped by supernumerary birds (Finn and Hughes 2001). Elsewhere, birds breed as unassisted pairs and young that cannot gain vacancies coalesce into small flocks that live in the interstices between territories while they await a chance to compete for a breeding vacancy (Carrick 1963, 1972). Extragroup mating has been studied for both singular and plural cooperatively breeding, and is high in both, though highest in the plural breeding case where natal dispersal is low (Durrant and Hughes 2005). There is limited sexual dimorphism, so little evidence of sexual selection. It has therefore been argued that extra-group mating is an inbreeding avoidance strategy (Durrant and Hughes 2005, 2006). By contrast, in the Cape Sugarbird (Promerops cafer), which can defend areas year-round but does not breed cooperatively, a high rate of infidelity is associated with strong sexual selection for tail elongation, suggesting that females are distinguishing characteristics of males that might benefit their offspring (McFarlane et al. 2010a, 2010b).

\section{Hypotheses for the high incidence of extra-group mating in Malurus}

\section{Incest avoidance}

The sequence of events that led to the discovery of the high incidence of extra-group mating in Malurus shaped the first of the hypotheses used to explain infidelity. Ian Rowley and Eleanor Russell had conducted long-term studies on Redwinged and Splendid (M. splendens splendens) Fairy-wrens in south-western Australia (Russell and Rowley 1993, 2000; Rowley and Russell 1997), where the incidence of female philopatry and helping behaviour was much higher than in other populations of Malurus. It is not clear why female philopatry is more pronounced in this region, but females can be very longlived, so territorial vacancies may become available less often than they do elsewhere (Rowley and Russell 1997).

The philopatry and passive queuing of male fairy-wrens is highest among cooperative breeders, and in most species can lead to males inheriting the dominant position while their mother is still on their territory (Cockburn et al. 2008b). In these situations, the female continues to breed, although she usually divorces and disperses to take up a breeding vacancy as soon as possible elsewhere, so the frequency of broods produced in the case of mother-son pairings is very low (Cockburn et al. 2003). However, female philopatry in the south-western populations can lead to a much richer array of possibilities, as pairings between father and daughter, or between siblings also become likely. Rowley et al. (1986) showed that the young produced from such incestuous social pairings did not suffer any obvious inbreeding depression, a result which excited interest in a conservation biology literature preoccupied with the risk of inbreeding depression in small populations. The importance of these results led to the application of allozyme methods to confirm whether the offspring had really resulted from incestuous matings (Rowley and Russell 1990). Even these low-resolution methods demonstrated high rates of infidelity and an extremely high prevalence of extra-group mating, and led to the argument that extra-group mating in fairy-wrens had evolved because of the high incidence of incestuous social pairings (Brooker et al. 1990). 
This hypothesis makes the testable prediction that extragroup fertilisation should be lower or absent in species or populations where incestuous pairing is very rare. This prediction was unambiguously rejected by the demonstration that extragroup fertilisations was very high in a species where incestuous pairing occurred at a negligible level (Mulder et al. 1994). Nonetheless, the inbreeding avoidance hypothesis has occasionally been revived, and supported with the observation that the frequency of extra-pair paternity within populations is highest when the social pair are closely related (Tarvin et al. 2005; Brouwer et al. 2011). In the best demonstration of this effect, Varian-Ramos and Webster (2012) used removal experiments to manipulate the relatedness of pairs in Red-backed Fairywrens by promoting males to pair with their mother, and increased extra-group mating as a consequence.

Although interesting, we do not think that these data provide convincing evidence for the original hypothesis that extra-group mating evolved to mitigate inbreeding avoidance. We are particularly influenced by our own observation that in every fertile period, female Superb Fairy-wrens mate with both an extra-group male and her social partner, except when they are paired to their son, in which case they ignore him completely (Calhim et al. 2011; A. Cockburn and M. C. Double, unpubl. obs.). Hence, while the observed variation in rates of extra-pair fertilisation is associated with a disinclination to engage in incestuous mating, all females seek extra-group matings regardless of relatedness, and presumably do so for reasons other than incest avoidance.

We do think that infidelity and incestuous pairing are connected, but that the causality is most likely in the opposite direction. According to this alternative view, once a high level of extra-pair matings has evolved, incestuous social pairing imposes little immediate costs on females because they can continue to produce outcrossed young by mating with extragroup males. In some species this means they can wait until a vacancy is available before dispersing (Cockburn 2013) and, in species where the availability of breeding vacancies is very low, high levels of female philopatry can emerge.

Indeed, one of the difficulties caused by a high rate of extragroup paternity is that individuals have poor knowledge of their relatedness to each other, so a female mating outside her group may well be mating with the male that sired her (Double et al. 2005). Because female dispersal in most species serves to remove the females from clusters of highly related males, this is most problematic in species where female philopatry has become very common. Brouwer et al. (2011) showed that in populations where males and females are philopatric, female Red-winged Fairy-wrens traverse greater distances to obtain extra-group fertilisations when their local neighbourhood contains more highly related males. It remains unknown how females determine that they are surrounded by their male relatives, but these results suggest that Malurus species with female philopatry may be particularly well suited for understanding whether birds can evolve sophisticated kin-recognition mechanisms that do not rely on the context in which the female was reared.

\section{Good genes}

The alternative view to incest avoidance is that, unlike most birds that form socially monogamous pairs, female fairy-wrens have achieved an unusual ability to cuckold their mates, and hence gain the benefits of choice of male genetic quality without risking the potential costs of desertion by their mate (Mulder et al. 1994). This view, which is similar to Gowaty's (1996) constrained female hypothesis, was motivated by the observation that female Superb Fairy-wrens are more reluctant to cuckold their mate completely if they lacked helpers (Mulder et al. 1994; Dunn and Cockburn 1999), a result that has since been observed in Splendid Fairy-wrens (subspecies melanotus) (Webster et al. 2004). This reluctance indicates that females are unwilling to cuckold their partner completely if they are entirely reliant on him for paternal investment but when helpers are available they take greater risks because they have an alternative source of care.

The hypothesis that females are selecting 'good genes' in males predicts that females would show predictable male choice for phenotypic traits of males that indicate their genetic quality, rather than simply mating with a male unrelated to them, in which case it can be difference or complementarity that is more important than a particular phenotype. In the species of Malurus in which extra-group fertilisations are prevalent, extra-group males seek extra-group matings with multimodal displays that involve four main cues.

The first cue is that all species with high rates of infidelity are strongly sexually dichromatic and display their brilliant plumage during courtship visits to females in their extended neighbourhood. These display forays have been called furgling (Strong 1990), a term originally coined by Ian Rowley (pers. comm.) and sourced from a description of the confused and generally ineffective attempts of Crazy Joe, a character in Joseph Heller's novel Catch 22, to photograph and court Italian women during the World War II.

Secondly, in some cases males carry flowers or flower parts when furgling (i.e. petal displays; Rowley 1991; Mulder 1997; Karubian and Alvarado 2003). The frequency of petal displays is difficult to compare between species, because petal-carrying increases the probability that males will be noticed, so only studies that systematically enumerate intrusions by males are likely to uncover the true incidence of petal-carrying. Unfortunately, the most intensive study has been carried out in a botanical garden where the availability of appropriate flower parts is artificially enhanced. However, even in these circumstances the frequency with which petals are carried on furgling trips is quite low ( 5\%; A. Cockburn, unpubl. obs.).

Thirdly, most species show variation in the duration of such courtship throughout the year, with the variation determined by age- and quality-related variation in the time that males are capable of maintaining their breeding plumage. In some species, notably in the bicoloured group that includes White-winged and Red-backed Fairy-wrens, variation in male appearance involves delayed plumage maturation, with young males often failing to acquire breeding plumage colouration despite being able to pair socially and hold territories (Karubian 2002; Webster et al. 2008). In most species, there is additional variation in the time of year in which males are in breeding plumage. Variation in this trait is only completely known for Superb Fairy-wrens, as most studies have not been able to monitor populations throughout the winter, when most variation is expressed. For most male Superb Fairy-wrens, post-breeding moult involves moult into a cryptic plumage resembling that of the female, but some older males use the 
moult to renew their breeding plumage, which they then hold throughout the non-breeding season. Other males can initiate the return to breeding plumage at any time of the year, including before the post-breeding moult is complete, and at the opposite extreme, after females have started to breed. The probability that males will moult well before the breeding season in Superb Fairy-wrens increases up to 9 years of age but among older birds is also facilitated by high rainfall in the months preceding the moult (Dunn and Cockburn 1999; Cockburn et al. 2008a; van de Pol and Cockburn 2011; van de Pol et al. 2012)

Finally, although both males and females in all species have songs that appear to function primarily in territorial defence, males in at least some species have an additional song (Type II or trill song), that is sung during the day in response to the calls or wing-beats of predators and other loud noises (Langmore and Mulder 1992; Dalziell and Cockburn 2008; Greig and PruettJones 2009; Greig et al. 2010). This song is also sung unprompted in the dawn chorus by incorporation into song sequences that include territorial songs (Dalziell and Cockburn 2008). The capacity of males to sing these songs also improves with age (Dalziell and Cockburn 2008).

There is growing evidence that it is how long males remain in breeding plumage, and hence display to females, that is the primary trait used by females to choose extra-group mates in all three groups of Australian fairy-wrens (Karubian 2002; Webster et al. 2004, 2008; Cockburn et al. 2008a; Brouwer et al. 2011). Although in some of these species the analysis involves a binary distinction (moult early versus moult late, delay plumage maturation or acquire nuptial plumage in the first year of life), in Superb Fairy-wrens the attractiveness (and fitness) of males increases consistently across the entire spectrum of moult timing, despite much indirect evidence for viability costs of breeding plumage (Peters 2000; Peters et al. 2000, 2001; Cockburn et al. 2008a).

\section{The behaviour underpinning extra-group mating}

Whereas courtship is observed repeatedly, with as many as 13 males having been recorded performing furgling displays to a female during a 30-min focal watch, there is no evidence that such courtship routinely leads to copulation. Indeed, as is true for many cooperatively breeding species, extra-group copulations are rarely or never observed during field studies.

The behaviour underpinning extra-pair mating was finally revealed when Double and Cockburn (2000) used radio-telemetry to show that extra-pair matings in Superb Fairy-wrens occur in a short window of time before dawn. Groups roost together overnight in dense shrubs. On most mornings during the breeding season, the first bird to leave such groups is the dominant male, who moves to sing in the dawn chorus, followed by any subordinate males shortly thereafter (Dalziell and Cockburn 2008). However, at any time in the period 4-2 days before the first egg of a clutch is laid, females can be the first to leave. They fly directly to the singing post of an extra-group male, copulate with him and then return to their home territory, typically arriving back close to sunrise (Double and Cockburn 2000). They then copulate with their partner (Calhim et al. 2011).

The detailed observational studies that led to these conclusions helped reveal an important feature of female choice in fairy-wrens that we predict may explain a lot of the variation in mating outcomes observed in natural populations of other taxa. Rather than assuming variation in mate choice is adaptive, it may reflect: (1) the cognitive complexity of choice, (2) the costs of delaying mate choice when females compete for sperm and (3) the selection imposed on males to exploit these opportunities.

Female Superb Fairy-wrens show several patterns that are compatible with errors and male counter-strategies rather than with adaptive mate choice. First, females mate with an extragroup male every time they become fertile, yet sometimes produce broods that are entirely sired by a male or males from the home group. We suspect that the success of the home male is not indicative of preference, but rather the failure of the female to ensure her preference is successfully consummated. The first difficulty she faces is that unless paired to her son, a female always mates with the males on the territory as well, presumably to encourage paternal investment, so the success of her preferred males depends on sperm competition. Calhim et al. (2011) showed that males with sperm that had long flagella and relatively small heads were superior at obtaining within-pair paternity, perhaps because this morphology allows the sperm to burrow past the sperm from the extra-group males that may have filled the sperm storage tubules, as the foreign male always mates first. The second difficulty is that the attractive extra-group sires are likely to be preferred by several females, and Cockburn et al. (2009) showed that some males could potentially attract visits from more than one female on a particular morning. Because males compete through the production of enormous ejaculates (Tuttle and Pruett-Jones 2004, 2007), it is conceivable that the preferred male would suffer from sperm depletion once he has copulated with the first female to visit him that morning.

Indeed, Double and Cockburn (2000) invoked the risk of sperm depletion as one reason why females leave to seek extragroup matings while it is still dark, as the earlier they copulate the better the chance of obtaining a high-quality ejaculate. However, by leaving so early, they reduce the value of visual cues in distinguishing their preferred male. This imposes selection on low-quality males to exploit this uncertainty. In Superb Fairy-wrens, females making these forays rarely encounter a single male, as attractive males are surrounded by both their subordinates and low-quality males from neighbouring territories, which sing as close to them as they can (Cockburn et al. 2009). Despite the ability to sing several song dialects, males in singing clusters adopt a common dialect of the trill song during the dawn chorus. The behaviour of males in the clusters appears to be competitive rather than cooperative, as there is no per capita benefit of congregation, and dominants males always attack their helpers during the dawn chorus. The subordinates therefore act as reproductive parasites, and are frequently successful at exploiting the attractiveness of their dominants. Even unattractive helpers of attractive males are more successful at garnering extra-pair fertilisations than unattractive dominants (Double and Cockburn 2003).

The third difficulty faced by females is their reliance on a display of endurance in consummating mate choice (Dunn and Cockburn 1999). Subordinates also gain carryover benefits if dominants die close to the start of the breeding season, apparently because the female is incapable of recognising that 
the high-quality male that attracted them to the territory is no longer present and still seeks copulations on that territory with other males that are still displaying (Cockburn et al. 2009).

Fourth, and also as a consequence of selecting males on the basis of their performance over many months, females have to discriminate those males from the much larger number that will be courting them by the start of the breeding season, and be able to find them, in the dark, among a cacophony of singing males. There are several lines of evidence that suggest this task is not trivial. First, it is usually the case that where females produce offspring sired by more than one extra-group male, those males will share a territory or be immediate neighbours. However, where there are exceptions, the males are usually situated in exactly opposed directions from the territory of the female (Double and Cockburn 2003). Exact reversal of direction of this sort indicated that the vector is clear, but that the direction of travel is confused. Even more puzzling, females receive information about the prowess of males on their own territory during furgling visits (Green et al. 1995, 2000; Mulder 1997), so they require additional information not just as to his ability to display for a long time, but also where he can be found on his own territory, perhaps months later. We have investigated how males might communicate this information with little success: our working hypothesis is that the male encodes spatial information during furgling displays; the sea-horse flight (Rowley and Russell 1997) is a candidate cue for direction.

Finally, male furgling begins months before the start of the breeding season, and must be maintained over that time despite considerable costs (Peters 2000; Peters et al. 2000, 2001). Males initiate signalling with only partial information about the future environment (Cockburn et al. 2008a; van de Pol et al. 2012), and the trait becomes an unreliable source of information to females under adverse environmental conditions as a consequence (Cockburn et al. 2008a). Despite the difficulties in consummating choice, females on average impose strong sexual selection on males by biasing reproductive success to a small number of extragroup males (Webster et al. 2007; Cockburn et al. 2008b; Brouwer et al. 2011).

\section{How is evolutionary stability achieved and why has it been lost in Purple-crowned Fairy-wrens?}

Because one of us has reviewed this topic recently (Cockburn 2013), we will summarise only briefly how obligate extra-group mating can persist despite the inevitable conflict. Cockburn (2004, 2013) points out that cooperatively breeding clades have often followed idiosyncratic evolutionary trajectories and show little convergence between unrelated species (see also Rubenstein 2012) but can show high stability within lineages. Such stability is particularly difficult to understand when the system appears to be undermined by intense conflict between different members of the society. In the case of fairy-wrens, dominant males suffer because of the actions of females and subordinates in several ways. First, females are more likely to cuckold them if they have helpers (Mulder et al. 1994; Dunn and Cockburn 1999), and when the helpers are related to the female, they gain a significant proportion of the limited within-pair fertilisations (Cockburn 2004; Cockburn et al. 2008b). Subordinates also are effective parasites of the attractiveness of extra-group males in Superb
Fairy-wrens (Double and Cockburn 2003; Cockburn et al. 2009). There appears to be no compensation. The presence of helpers does not enhance reproductive success on the territory (Cockburn et al. 2008c) and although dominants reduce provisioning of young in the presence of helpers, they gain neither enhanced survival (Cockburn et al. 2008c) nor improved ability to attract extra-group fertilisations (Green et al. 2000). By contrast, females enjoy sharply increased survival when they are assisted by helpers (Cockburn et al. 2008c) because they can reduce their investment in eggs owing to the increased provisioning the brood receives (Russell et al. 2007). Hence a single member of the social group (the dominant female) monopolises the benefits of cooperative care.

Cockburn (2013) proposes that Malurus are locked into this strategy by a history of coevolutionary interactions between males and females. This involves the following sequence:

(1) Because of long life and high population density, there is intense selection on females to find vacancies, so they settle without any assessment of mates.

(2) They compensate for lack of mate choice by seeking extrapair fertilisations, as proposed by Møller (1992).

(3) Males court females for a response and coerce help from subordinates (Mulder and Langmore 1993) so that they can reduce their provisioning rate.

(4) Females take advantage of the coercion to increase the rate of cuckoldry, tipping the balance of male fitness towards extra-group mating.

(5) Increasingly, it is the ability of males to display for a long time that becomes the target of selection.

(6) Because display and fertility become dissociated, females need to be able to find the displaying males at a later date, forcing males to defend a territory where they can be found.

(7) Females appease their own mate by copulating with them as well.

(8) Sperm competition between the home male and the extragroup sire leads to a large ejaculate strategy, with consequent limits on sperm replenishment.

(9) Females mate earlier and earlier during the day to avoid sperm depletion of the extra-group male.

(10) Subordinates (and unattractive males) evolve parasitic strategies to exploit the attractiveness of dominants.

According to this hypothesis the system is resilient to collapse for three reasons. First, extra-group success provides subordinates with a stabilising incentive for participation. Second, the asymmetry in reproductive success caused by the success of attractive dominants means that most offspring are descendants of such dominants, which undermines the evolution of alternative strategies. Third, the same asymmetry means that although most parentage is by extra-group fertilisation, most extra-group success is won by just a few males. Most males gain no such successes, and only gain parentage with the female on their own territory, providing an incentive to adopt a best-of-abad-job strategy, and invest in the offspring that she produces.

This view focuses attention on the reversion to high fidelity in Purple-crowned Fairy-wrens. Kingma et al. (2009) argued that the very different mating system of this species is associated with its unusual habitat dependency, which is the only feature that seems to distinguish them from other Malurus. Birds defend 
narrow territories along watercourses so that birds have neighbours only at the extreme ends of their territory, but not along most of their territorial boundary because habitat away from streams is unsuitable. They speculated that the linear configuration of territories would reduce the prospect of finding a highquality male, as the number of males encountered at progressive distances from the female increases linearly, in contrast to the geometric progression in more usual habitat configurations where the birds have neighbours in every direction. However, this effect is not strongly supported by the only two studies that test the distances that females will travel to mate with extragroup sires in conventional landscapes (Double and Cockburn 2003; Brouwer et al. 2011), which suggest that although females occasionally do move long distances to mate (up to 12 territories in Red-winged Fairy-wrens), the mode is just two territories in both species. Over this distance the difference between linear and geometric progression is likely to be modest, as territory configurations never attain the ideal where each female has six neighbours. Cockburn (2013) has presented the alternative hypothesis that both the signalling strategy used by dominant males and the information content that can be gleaned by females collapses in linear habitat. This is because any distant male will lure the female past all the intervening males when she seeks out his territory. This undermines the utility of the signalling convention.

\section{Conclusions}

In this review we have analysed the evolution of an extreme mating system, which lacks simple parallels elsewhere among birds. This extreme has meant that Malurus has become a model system for studying extra-pair mating, as its sheer prevalence has allowed the underlying behaviour to be better understood than has been achieved in any other species (Westneat and Stewart 2003). This represents another case where studying extreme systems has uncovered general points of fundamental importance. For example, understanding of the evolution of clutch-size has repeatedly been informed by studies of Palaearctic species of Parus and Cyanistes (e.g. Lack 1947; Perrins 1965), though the massive clutch-sizes in these species represent a dramatic extreme among the passerine birds to which these birds belong. Indeed, fairy-wrens have several characteristics that make them extremely well suited to advance our understanding of the benefits that females gain from mate choice.

Interpretations of the benefits that flow from female choice can be confounded by the possibility that females that have mated with attractive extra-pair males invest more in their offspring than those that have mated only with their partner (Sheldon 2000; Tschirren et al. 2012). So far as we are aware fairy-wrens are the only birds in which all females can and do mate with extra-group males from which they obtain nothing but sperm every single fertile period, so there is no basis for them restricting investment because their potential mate is unsatisfactory.

Second, at least one sex in species of Malurus is typically extremely philopatric (Cockburn et al. 2008b), which means that the fate of offspring can be followed easily throughout their lives. This greatly aids measurements of survival and reproduction of offspring. Finally, the combination of infidelity and philopatry means that fairy-wrens are ideally suited for estimating quantitative genetic parameters in natural populations (Kruuk 2004), as environmental covariance is disrupted as males can gain reproductive success on many different territories.

Finally, fairy-wrens constantly reward close study with charisma and fascinating behaviour. It is scarcely surprising that they are greatly over-represented among species that have been the subject of long-term studies (Russell and Rowley 1993, 2000; Rowley and Russell 1997; Cockburn et al. 2003, 2008b). Despite this effort, there is a great deal that remains to be done. How do the sexually monomorphic New Guinean species behave? What additional information is carried in apparently secondary cues like song and petal-carrying? How do females respond evolutionarily to parasitic strategies of males? How do females find males on their own territory? How does extra-group mating enhance offspring fitness?

\section{Acknowledgments}

Our research on fairy-wrens has been facilitated by grants from the Australian Research Council to Andrew Cockburn and Martijn van de Pol, a Rubicon fellowship to Lyanne Brouwer and a Swiss National Science Foundation Fellowship to Nico Margraf. Our behavioural research has depended on many field assistants, most notably Helen Osmond and David Green, and students, particularly Raoul Mulder, Anne Peters, Caroline Blackmore and Anastasia Dalziell, and has been generously tolerated by the Australian National Botanic Gardens (Canberra, ACT).

\section{References}

Birkhead, T. R., and Møller, A. P. (1992). 'Sperm Competition in Birds: Evolutionary Causes and Consequences.' (Academic Press: London.)

Bitton, P.-P., O’Brien, E. L., and Dawson, R. D. (2007). Plumage brightness and age predict extrapair fertilization success of male Tree Swallows, Tachycineta bicolor. Animal Behaviour 74, 1777-1784. doi:10.1016/j. anbehav.2007.03.018

Bouwman, K. M., and Komdeur, J. (2005). Old female Reed Buntings (Emberiza schoeniclus) increase extra-pair paternity in their broods when mated to young males. Behaviour 142, 1449-1463. doi:10.1163/ 156853905774831819

Bouwman, K. M., Burke, T., and Komdeur, J. (2006). How female Reed Buntings benefit from extra-pair mating behaviour: testing hypotheses through patterns of paternity in sequential broods. Molecular Ecology 15, 2589-2600. doi:10.1111/j.1365-294X.2006.02955.x

Bouwman, K. M., Van Dijk, R. E., Wijmenga, J. J., and Komdeur, J. (2007). Older male Reed Buntings are more successful at gaining extrapair fertilizations. Animal Behaviour 73, 15-27. doi:10.1016/j.anbehav. 2006.01.031

Brooker, M. G., Rowley, I., Adams, M., and Baverstock, P. R. (1990). Promiscuity: an inbreeding avoidance mechanism in a socially monogamous species? Behavioral Ecology and Sociobiology 26, 191-200.

Brouwer, L., van de Pol, M., Atema, E., and Cockburn, A. (2011). Strategic promiscuity helps avoid inbreeding at multiple levels in a cooperative breeder where both sexes are philopatric. Molecular Ecology 20, 4796-4807. doi:10.1111/j.1365-294X.2011.05325.x

Calhim, S., Double, M. C., Margraf, N., Birkhead, T. R., and Cockburn, A. (2011). Maintenance of sperm variation in a highly promiscuous wild bird. PLOS ONE 6, e28809. doi:10.1371/journal.pone.0028809

Carrick, R. (1963). Ecological significance of territory in the Australian Magpie, Gymnorhina tibicen. Proceedings of the International Ornithological Congress 13, 740-753. doi:10.1371/journal.pone.0028809

Carrick, R. (1972). Population ecology of the Australian black-backed magpie, Royal Penguin and Silver Gull. US Department of the Interior Internal Wildlife Reports 2, 41-99. 
Coates, B. J. (1990). 'The Birds of Papua New Guinea. Vol. 2: Passerines.' (Dove Publications: Alderley, Qld.)

Cockburn, A. (2004). Mating systems and sexual conflict. In 'Ecology and Evolution of Cooperative Breeding in Birds.' (Eds W. D. Koenig and J. L. Dickinson.) pp. 81-101. (Cambridge University Press: Cambridge, UK.)

Cockburn, A. (2006). Prevalence of different modes of parental care in birds. Proceedings of the Royal Society of London-B. Biological Sciences 273, 1375-1383. doi:10.1098/rspb.2005.3458

Cockburn, A. (2013). Cooperative breeding in birds: towards a richer conceptual framework. In 'Cooperation and its Evolution.' (Eds K. Sterelny, R. Joyce, B. Calcott and B. Fraser.) pp. 223-245. (MIT Press: Cambridge, MA.)

Cockburn, A., Osmond, H. L., Mulder, R. A., Green, D. J., and Double, M. C. (2003). Divorce, dispersal and incest avoidance in the cooperatively breeding Superb Fairy-wren Malurus cyaneus. Journal of Animal Ecology 72, 189-202. doi:10.1046/j.1365-2656.2003.00694.x

Cockburn, A., Osmond, H. L., and Double, M. C. (2008a). Swingin' in the rain: condition dependence and sexual selection in a capricious world. Proceedings of the Royal Society of London - B. Biological Sciences 275, 605-612. doi:10.1098/rspb.2007.0916

Cockburn, A., Osmond, H. L., Mulder, R. A., Double, M. C., and Green, D. J. $(2008 b)$. Demography of male reproductive queues in cooperatively breeding Superb Fairy-wrens Malurus cyaneus. Journal of Animal Ecology 77, 297-304. doi:10.1111/j.1365-2656.2007.01335.x

Cockburn, A., Sims, R. A., Osmond, H. L., Green, D. J., Double, M. C., and Mulder, R. A. (2008c). Can we measure the benefits of help in cooperatively breeding birds: the case of Superb Fairy-wrens Malurus cyaneus? Journal of Animal Ecology 77, 430-438. doi:10.1111/j.1365-2656. 2007.01351.x

Cockburn, A., Dalziell, A. H., Blackmore, C. J., Double, M. C., Kokko, H., Osmond, H. L., Beck, N. R., Head, M. L., and Wells, K. (2009). Superb Fairy-wren males aggregate into hidden leks to solicit extragroup fertilizations before dawn. Behavioral Ecology 20, 501-510. doi:10.1093/ beheco/arp024

Colombelli-Négrel, D., Schlotfeldt, B. E., and Kleindorfer, S. (2009). High levels of extra-pair paternity in Superb Fairy-wrens in South Australia despite low frequency of auxiliary males. Ети 109, 300-304. doi:10.1071/MU09035

Dalziell, A. H., and Cockburn, A. (2008). Dawn song in Superb Fairy-wrens: a bird that seeks extrapair copulations during the dawn chorus. Animal Behaviour 75, 489-500. doi:10.1016/j.anbehav.2007.05.014

Dixon, A., Ross, D., O’Malley, S. L. C., and Burke, T. (1994). Paternal investment inversely related to degree of extra-pair paternity in the Reed Bunting. Nature 371, 698-700. doi:10.1038/371698a0

Double, M., and Cockburn, A. (2000). Pre-dawn infidelity: females control extra-pair mating in Superb Fairy-wrens. Proceedings of the Royal Society of London - B. Biological Sciences 267, 465-470. doi:10.1098/rspb.2000.1023

Double, M. C., and Cockburn, A. (2003). Subordinate Superb Fairy-wrens (Malurus cyaneus) parasitize the reproductive success of attractive dominant males. Proceedings of the Royal Society of London B. Biological Sciences 270, 379-384. doi:10.1098/rspb.2002.2261

Double, M. C., Peakall, R., Beck, N. R., and Cockburn, A. (2005). Dispersal, philopatry, and infidelity: dissecting local genetic structure in Superb Fairy-wrens (Malurus cyaneus). Evolution 59, 625-635.

Driskell, A. C., Norman, J. A., Pruett-Jones, S., Mangall, E., Sonsthagen, S., and Christidis, L. (2011). A multigene phylogeny examining evolutionary and ecological relationships in the Australo-papuan wrens of the subfamily Malurinae (Aves). Molecular Phylogenetics and Evolution 60, 480-485. doi:10.1016/j.ympev.2011.03.030

Dunn, P. O., and Cockburn, A. (1999). Extrapair mate choice and honest signaling in cooperatively breeding Superb Fairy-wrens. Evolution 53, 938-946. doi:10.2307/2640733
Dunn, P. O., Cockburn, A., and Mulder, R. A. (1995). Fairy-wren helpers often care for young to which they are unrelated. Proceedings of the Royal Society of London - B. Biological Sciences 259, 339-343. doi:10.1098/rspb.1995.0050

Dunn, P. O., Lifjeld, J. T., and Whittingham, L. A. (2009). Multiple paternity and offspring quality in Tree Swallows. Behavioral Ecology and Sociobiology 63, 911-922. doi:10.1007/s00265-009-0734-5

Durrant, K. L., and Hughes, J. M. (2005). Differing rates of extra-group paternity between two populations of the Australian Magpie (Gymnorhina tibicen). Behavioral Ecology and Sociobiology 57, 536-545. doi:10.1007/ s00265-004-0883-5

Durrant, K. L., and Hughes, J. M. (2006). Are there correlates of male Australian Magpie Gymnorhina tibicen reproductive success in a population with high rates of extra-group paternity? Ibis 148, 313-320. doi:10.1111/j.1474-919X.2006.00539.x

Finn, P. G., and Hughes, J. M. (2001). Helping behaviour in Australian Magpies, Gymnorhina tibicen. Ети 101, 57-63. doi:10.1071/MU00066

Friedman, N. R., Hofmann, C. M., Kondo, B., and Omland, K. E. (2009). Correlated evolution of migration and sexual dichromatism in the New World orioles (Icterus). Evolution 63, 3269-3274. doi:10.1111/j.15585646.2009.00792.x

Gardner, J. L., Trueman, J. W. H., Ebert, D., Joseph, L., and Magrath, R. D. (2010). Phylogeny and evolution of the Meliphagoidea, the largest radiation of Australasian songbirds. Molecular Phylogenetics and Evolution 55, 1087-1102. doi:10.1016/j.ympev.2010.02.005

Gowaty, P. A. (1996). Battle of the sexes and the origins of monogamy. In 'Partnerships in Birds: The Study of Monogamy.' (Ed. J. M. Black.) pp. 21-52. (Oxford University Press: Oxford, UK.)

Green, D. J., Cockburn, A., Hall, M. L., Osmond, H., and Dunn, P. O. (1995). Increased opportunities for cuckoldry may be why dominant male fairywrens tolerate helpers. Proceedings of the Royal Society of LondonB. Biological Sciences 262, 297-303. doi:10.1098/rspb.1995.0209

Green, D. J., Osmond, H. L., Double, M. C., and Cockburn, A. (2000). Display rate by male fairy-wrens (Malurus cyaneus) during the fertile period of females has little influence on extra-pair mate choice. Behavioral Ecology and Sociobiology 48, 438-446. doi:10.1007/s002650000258

Greig, E. I., and Pruett-Jones, S. (2009). A predator-elicited song in the Splendid Fairy-wren: warning signal or intraspecific display? Animal Behaviour 78, 45-52. doi:10.1016/j.anbehav.2009.02.030

Greig, E. I., Spendel, K., and Brandley, N. C. (2010). A predator-elicited vocalisation in the Variegated Fairy-wren (Malurus lamberti). Emu 110, 165-169. doi:10.1071/MU09107

Griffith, S. C., Owens, I. P. F., and Thuman, K. A. (2002). Extra pair paternity in birds: a review of interspecific variation and adaptive function. Molecular Ecology 11, 2195-2212. doi:10.1046/j.1365-29 4X.2002.01613.x

Hughes, J. M., Mather, P. B., Toon, A., Ma, J., Rowley, I., and Russell, E. (2003). High levels of extra-group paternity in a population of Australian Magpies Gymnorhina tibicen: evidence from microsatellite analysis. Molecular Ecology 12, 3441-3450. doi:10.1046/j.1365-294X.2003. 01997.x

Joseph, L., Edwards, S. V., and McLean, A. J. (2013). The Maluridae: inferring avian biology and evolutionary history from DNA sequences. Ети 113, 195-207. doi:10.1071/MU12081

Karubian, J. (2001). The social organization and mating system of the Striated Grasswren. Condor 103, 412-417. doi:10.1650/0010-5422 (2001)103[0412:TSOAMS]2.0.CO;2

Karubian, J. (2002). Costs and benefits of variable breeding plumage in the Red-backed Fairy-wren. Evolution 56, 1673-1682.

Karubian, J., and Alvarado, A. (2003). Testing the function of petal-carrying in the Red-backed Fairy-wren (Malurus melanocephalus). Еmu 103, 87-92. doi:10.1071/MU01063

Kempenaers, B., Congdon, B., Boag, P., and Robertson, R. J. (1999). Extrapair paternity and egg hatchability in Tree Swallows: evidence 
for the genetic compatibility hypothesis? Behavioral Ecology 10, 304-311. doi:10.1093/beheco/10.3.304

Kingma, S. A., Hall, M. L., Segelbacher, G., and Peters, A. (2009). Radical loss of an extreme extra-pair mating system. BMC Ecology 9, 15. doi:10.1186/1472-6785-9-15

Kleven, O., and Lifjeld, J. T. (2004). Extrapair paternity and offspring immunocompetence in the Reed Bunting, Emberiza schoeniclus. Animal Behaviour 68, 283-289. doi:10.1016/j. anbehav.2003.11.016

Kleven, O., and Lifjeld, J. T. (2005). No evidence for increased offspring heterozygosity from extrapair mating in the Reed Bunting (Emberiza schoeniclus). Behavioral Ecology 16, 561-565. doi:10.1093/beheco/ ari027

Kruuk, L. E. B. (2004). Estimating genetic parameters in natural populations using the 'animal model'. Philosophical Transactions of the Royal Society of London - B. Biological Sciences 359, 873-890. doi:10.1098/ rstb.2003.1437

Lack, D. (1947). The significance of clutch size. Ibis 89, 302-352. doi:10.1111/j.1474-919X.1947.tb04155.x

Langmore, N. E., and Mulder, R. A. (1992). A novel context for bird song: predator calls prompt male singing in the kleptogamous Superb Fairywren, Malurus cyaneus. Ethology 90, 143-153. doi:10.1111/j.14390310.1992.tb00828.x

Lee, J. Y., Joseph, L., and Edwards, S. V. (2012). A species tree for the Australo-Papuan fairy-wrens and allies (Aves:Maluridae). Systematic Biology 61, 253-271. doi:10.1093/sysbio/syr101

Maguire, G. S., and Mulder, R. A. (2008). Low levels of extra-pair paternity in Southern Emu-wrens (Aves : Maluridae). Australian Journal of Zoology 56, 79-84. doi:10.1071/ZO08047

McFarlane, M. L., Cherry, M. I., and Evans, M. R. (2010a). Female Cape Sugarbirds (Promerops cafer) modify egg investment both for extra-pair mates and for male tail length. Journal of Evolutionary Biology 23, 1998-2003. doi:10.1111/j.1420-9101.2010.02067.x

McFarlane, M. L., Evans, M. R., Feldheim, K. A., Preault, M., Bowie, R. C. K., and Cherry, M. I. (2010b). Long tails matter in sugarbirds: positively for extra-pair but negatively for within-pair fertilization success. Behavioral Ecology 21, 26-32. doi:10.1093/beheco/arp147

Møller, A. P. (1992). Frequency of female copulations with multiple males and sexual selection. American Naturalist 139, 1089-1101. doi:10.1086/ 285374

Mulder, R. A. (1997). Extra-group courtship displays and other reproductive tactics of Superb Fairy-wrens. Australian Journal of Zoology 45, 131-143. doi:10.1071/ZO96041

Mulder, R. A., and Langmore, N. E. (1993). Dominant males punish helpers for temporary defection in Superb Fairy-wrens. Animal Behaviour 45, 830-833. doi:10.1006/anbe.1993.1100

Mulder, R. A., Dunn, P. O., Cockburn, A., Lazenby-Cohen, K. A., and Howell, M. J. (1994). Helpers liberate female fairy-wrens from constraints on extra-pair mate choice. Proceedings of the Royal Society of London - B. Biological Sciences 255, 223-229. doi:10.1098/ rspb.1994.0032

Perrins, C. M. (1965). Population fluctuation and clutch-size in the Great Tit, Parus major L. Journal of Animal Ecology 34, 601-647. doi:10.2307/ 2453

Peters, A. (2000). Testosterone treatment is immunosuppressive in Superb Fairy-wrens, yet free-living males with high testosterone are more immunocompetent. Proceedings of the Royal Society of London B. Biological Sciences 267, 883-889. doi:10.1098/rspb.2000.1085

Peters, A., Astheimer, L. B., Boland, C. R. J., and Cockburn, A. (2000). Testosterone is involved in acquisition and maintenance of sexually selected male plumage in Superb Fairy-wrens, Malurus cyaneus. Behavioral Ecology and Sociobiology 47, 438-445. doi:10.1007/ s002650050688

Peters, A., Astheimer, L. B., and Cockburn, A. (2001). The annual testosterone profile in cooperatively breeding Superb Fairy-wrens,
Malurus cyaneus, reflects their extreme infidelity. Behavioral Ecology and Sociobiology 50, 519-527. doi:10.1007/s002650100403

Rowe, M., and Pruett-Jones, S. (2008). Reproductive anatomy of male Southern Emu-wrens (Stipiturus malachurus) and Striated Grasswrens (Amytornis striatus). Emu 108, 68-73. doi:10.1071/MU07057

Rowley, I. (1991). Petal-carrying by fairy-wrens of the genus Malurus. Australian Bird Watcher 14, 75-81.

Rowley, I., and Russell, E. (1990). Philandering: a mixed mating strategy in the Splendid Fairy-wren Malurus splendens. Behavioral Ecology and Sociobiology 27, 431-437. doi:10.1007/BF00164070

Rowley, I., and Russell, E. (1997). 'Fairy-wrens and Grasswrens: Maluridae.' (Oxford University Press: Oxford, UK.)

Rowley, I., Russell, E., and Brooker, M. (1986). Inbreeding: benefits may outweigh costs. Animal Behaviour 34, 939-941. doi:10.1016/S00033472(86)80086-0

Rubenstein, D. R. (2012). Family feuds: social competition and sexual conflict in complex societies. Philosophical Transactions of the Royal Society of London-B. Biological Sciences 367, 2304-2313. doi:10.1098/ rstb.2011.0283

Russell, E. M., and Rowley, I. (1993). Demography of the cooperatively breeding Splendid Fairy-wren, Malurus splendens (Maluridae). Australian Journal of Zoology 41, 475-505. doi:10.1071/ZO9930475

Russell, E., and Rowley, I. (2000). Demography and social organisation of the Red-winged Fairy-wren, Malurus elegans. Australian Journal of Zoology 48, 161-200. doi:10.1071/ZO99066

Russell, A. F., Langmore, N. E., Cockburn, A., Astheimer, L. B., and Kilner, R. M. (2007). Reduced egg investment can conceal helper effects in cooperatively breeding birds. Science 317, 941-944. doi:10.1126/ science. 1146037

Schmoll, T. (2011). A review and perspective on context-dependent genetic effects of extra-pair mating in birds. Journal of Ornithology 152, 265-277. doi:10.1007/s10336-011-0683-4

Schodde, R., and Weatherly, R. (1982). 'The Fairy-wrens: a Monograph of the Maluridae.' (Lansdowne: Melbourne.)

Sheldon, B. C. (2000). Differential allocation: tests, mechanisms and implications. Trends in Ecology \& Evolution 15, 397-402. doi:10.1016/S0169-5347(00)01953-4

Stapleton, M. K., Kleven, O., Lifjeld, J. T., and Robertson, R. J. (2007). Female Tree Swallows (Tachycineta bicolor) increase offspring heterozygosity through extrapair mating. Behavioral Ecology and Sociobiology 61, 1725-1733. doi:10.1007/s00265-007-0404-4

Strong, M. (1990). Furgling by the Red-backed Fairy-wren. Sunbird 20, $37-38$.

Suter, S. M., Keiser, M., Feignoux, R., and Meyer, D. R. (2007). Reed Bunting females increase fitness through extra-pair mating with genetically dissimilar males. Proceedings of the Royal Society of London - B. Biological Sciences 274, 2865-2871. doi:10.1098/ rspb.2007.0799

Suter, S. M., Bielanska, J., Roethlin-Spillmann, S., Strambini, L., and Meyer, D. R. (2009). The cost of infidelity to female Reed Buntings. Behavioral Ecology 20, 601-608. doi:10.1093/beheco/arp037

Tarvin, K. A., Webster, M. S., Tuttle, E. M., and Pruett-Jones, S. (2005). Genetic similarity of social mates predicts the level of extrapair paternity in Splendid Fairy-wrens. Animal Behaviour 70, 945-955. doi:10.1016/j.anbehav.2005.01.012

Tschirren, B., Postma, E., Rutstein, A. N., and Griffith, S. C. (2012). When mothers make sons sexy: maternal effects contribute to the increased sexual attractiveness of extra-pair offspring. Proceedings of the Royal Society of London- B. Biological Sciences 279, 1233-1240. doi:10.1098/ rspb.2011.1543

Tuttle, E. M., and Pruett-Jones, S. (2004). Estimates of extreme sperm production: morphological and experimental evidence from reproductively promiscuous fairy-wrens (Malurus). Animal Behaviour 68, 541-550. doi:10.1016/j.anbehav.2003.09.014 
Tuttle, E. M., and Pruett-Jones, S. (2007). Erratum. Animal Behaviour 73, 555-556. doi:10.1016/j.anbehav.2006.12.003

van de Pol, M., and Cockburn, A. (2011). Identifying the critical climatic time window that affects trait expression. American Naturalist 177, 698-707. doi:10.1086/659101

van de Pol, M., Osmond, H. L., and Cockburn, A. (2012). Fluctuations in population composition dampen the impact of phenotypic plasticity on trait dynamics in Superb Fairy-wrens. Journal of Animal Ecology 81, 411-422. doi:10.1111/j.1365-2656.2011.01919.x

Varian-Ramos, C. W., and Webster, M. S. (2012). Extrapair copulations reduce inbreeding for female Red-backed Fairy-wrens, Malurus melanocephalus. Animal Behaviour 83, 857-864. doi:10.1016/j.anbehav.2012. 01.010

Webster, M. S., Tarvin, K. A., Tuttle, E. M., and Pruett-Jones, S. (2004). Reproductive promiscuity in the Splendid Fairy-wren: effects of group size and auxiliary reproduction. Behavioral Ecology 15, 907-915. doi:10.1093/beheco/arh093

Webster, M. S., Tarvin, K. A., Tuttle, E. M., and Pruett-Jones, S. (2007). Promiscuity drives sexual selection in a socially monogamous bird. Evolution 61, 2205-2211. doi:10.1111/j.1558-5646.2007.00208.x

Webster, M. S., Varian-Ramos, C. W., and Karubian, J. (2008). Plumage color and reproduction in the Red-backed Fairy-wren: why be a dull breeder? Behavioral Ecology 19, 517-524. doi:10.1093/beheco/arn015

Westneat, D. F., and Stewart, I. R. K. (2003). Extra-pair paternity in birds: causes, correlates, and conflict. Annual Review of Ecology Evolution and Systematics 34, 365-396. doi:10.1146/annurev.ecolsys.34.011802. 132439

Whittingham, L. A., Dunn, P. O., and Stapleton, M. K. (2006). Repeatability of extra-pair mating in Tree Swallows. Molecular Ecology 15, 841-849. doi:10.1111/j.1365-294X.2006.02808.x 